\title{
Smoking Prevalence, Attitude, Knowledge and Practice Among Applied Medical Sciences Saudi Students in King Abdalaziz University
}

\author{
Shehab M Abd El Kader ${ }^{2}$ and Ahmed A Al Ghamdi1* \\ ${ }^{1}$ Department of Medical Laboratory Technology, King Abdulaziz University, Saudi Arabia \\ ${ }^{2}$ Department of Physical Therapy for Cardiopulmonary Disorders and Geriatrics, Cairo University, Egypt
}

Submission: January 05, 2018; Published: February 08, 2018

*Corresponding author: Shehab M Abd El Kader, Department of Physical Therapy, Faculty of Applied Medical Sciences, King Abdulaziz University, P.O. Box 80324, Jeddah, 21589, Saudi Arabia, Email: profshehab@live.com

\section{Abstact}

Background: Smoking is one of the major causes of death as and it has been predicted to cause the deaths of 10 million per year by 2020 worldwide. However, In Saudi Arabia, tobacco consumption is a major public health problem, with increasing use among adolescents.

Objective: The aim of this study was to detect smoking prevalence, attitude, knowledge and practice among Applied Medical Sciences Saudi students in King Abdalaziz University.

Material and Methods: The present study included 494 students who are in the $2^{\text {nd }}$ to the $4^{\text {th }}$ year participated in this study. Hard copy questionnaire were distributed among the students during lecture times. The questionnaire was composed of four sections. The first section contained the questions related to demographic data (Gender, age, marital status etc.) of the participants. Second section of the questionnaire which contained 3 questions in total was about the knowledge of students regarding effects of smoking on health. Third section was about the general attitude of participants regarding smoking and it contained 11 questions. The fourth and last section contained 9 questions about the practicing of smoking among medical students and family members as well. The questionnaire was anonymous, self-written and adopted from Global Adult Tobacco Survey (GATS). The questionnaire takes around 10 minutes to be answered.

Results: The current study revealed a considerable higher prevalence of smoking among male than female students in Faculty of Applied Medical Sciences, King Abdul-Aziz University, Jeddah City, Saudi Arabia. One of the major and important findings of this current study was the positive attitudes of all studied students and smokers in particular towards smoking.

Conclusion: This finding of this study has to motivate and encourage the Ministry of Health to increase the number of smoking clinics and activate them and make them more popular and attract the smoker students to utilize helping them to quit smoking. In addition, it would be very helpful to organize smoking campaigns in the various faculties at the university to increase the awareness about the dangerous of smoking.

Keywords: Smoking; Prevalence; Attitude; Students; Saudi arabia

\section{Introduction}

World Health Organization (WHO) 2015, reported that case fatality rate in case of tobacco smoking addiction is more than $15 \%$ of the total population around the globe. Estimates in 2015 have shown that 6 million people die because of direct cost of tobacco smoking (or other less common addiction methods). More than 3/4th of all such deaths are due to direct smoking causes; and the rest are attributed to passive smoking. Nearly $80 \%$ of smokers are residents of low or middle income and/or developing countries [1].

In Saudi Arabia, for the general population many studies investigated the prevalence of smokers. These studies indicated that the prevalence of current smoking in Saudi Arabia ranged between (9-35\%), and among school students, the smoking prevalence was $16.5 \%$, in university students $13.5 \%$, among adults $22.6 \%$, elderly peoples $25 \%$, and males $26.5 \%$ while in females $9 \%$ [2-4].

In fact, some studies investigated the prevalence of smokers among Saudi universities and colleges students in general, which found to be $14.5 \%$ [5]. Other studies focused on students who study in the health colleges (such as medicine and dentistry), and found the prevalence to be $16 \%$, which considered be higher than the previous percentage, and when it compared male students in different health colleges on a national scale in Saudi Arabia as (Central: Kind Saud University ,King Fahad Medical City, Qassim university; North: Aljouf university, Hail university, Tabuk university ;South: Najran university, Jazan university, King Khalid University; East: Dammam university; and West: King Abdulaziz University and Taibah university) and indicated that 
dental students smoke more than medicine students [6]. As the prevalence among dental students was $18 \%$ compared to medical students with a prevalence of $14 \%$.However, this study did not include females, and did not consider Universities of Makkah city, despite the fact Makkah is considered one of the major cities nationally. Furthermore, a recent study was conducted in Najran university among health college students and found that the prevalence of smoking in male and female students $(30.1 \%$, $0.5 \%$ ) respectively, the students at the college of applied medical sciences had the highest prevalence of smoking 34\% followed by the students at colleges of pharmacy (15\%) and dentistry (9\%), and the lowest prevalence (4\%) was at the college of medicine [7].

During medical school education, students are considered more cautious and logical about the hazards of smoking. However, opposite situation has been noticed in this case, as medical students are more likely to become smokers during their medical studies and an increase in the consumption of tobacco has noticed for the students who are already smokers. However, medical college students are different from non-medical college students as they are more likely to become occasional smokers [8].

There were no smokers in the first year of medical course but in the final year prevalence was $45.5 \%$ in Bahrain [9]. However, there is a study to measure the prevalence of smokers in the Umm al-Qura in college of medicine among male students and found that the prevalence of smoking was 30\% [10]. According to our knowledge there was no previous studies carried out to investigate smoking among undergraduate students of Applied Medical Sciences in King Abdalaziz University. Thus, the aim of the present study was to detect smoking prevalence, attitude, knowledge and practice among Applied Medical Sciences Saudi students in King Abdalaziz University.

\section{Subjects \& Methods}

\section{Research design}

A descriptive cross-sectional study was conducted among students of the Faculty of Applied Medical Sciences in King Abdalaziz University, Jeddah, Saudi Arabia, from 10 September to 7 December 2017 with the aim of assessing their awareness, attitudes and practices of smoking. The survey was conducted with permission and an approval from the Ethical Research board at the faculty of Applied Medical Sciences, King Abdalaziz University. As there have been no invasive procedure would be used, only verbal consent was taken from the participants.

\section{Settings}

This study was conducted in the Faculty of Applied Medical Sciences, included Department of Medical Laboratory Technology, Department of Diagnostic Radiology, Department of Physical Therapy and Department of Clinical Nutrition in King Abdalaziz University.

\section{Subjects of the study}

A sample of 494 students at the faculty of Applied Medical Sciences, King Abdalaziz University, Saudi Arabia who are in the $2^{\text {nd }}$ to the $4^{\text {th }}$ year was included in this study. Students in the $1^{\text {st }}$ (preparatory year) and interns were excluded from this study. A hard copy questionnaire was distributed among students. Inclusion criteria included students who accepted to participate in this study, while exclusion criteria included students who refused to give informed consent. The questionnaire was disseminated to the students during lecture times by the assistance of the academic office in each college, and after the permission of lecturers, to be filled after the lecture time. The data collector was available to answer any question raised by students. After students fill the questionnaires, they were taken back.

\section{Instrumentation}

The data of the study was collected through a self-written questionnaire which was mainly adopted from Global Adult Tobacco Survey (GATS). This survey has been developed by many organizations and institutes including World Health Organization (WHO) and Centers of Disease Control and Prevention (CDC), and was designed to assess major issues related to smoking. The validity of the questions could be assumed as the same questionnaire has been used in many previous studies, in addition to the validation of the developing institutes $[11,12]$. The questionnaire has translated into Arabic language, and had been modified according to the local culture and religion. Another researcher to ensure accuracy did back translation. The questionnaire included 31 core questions related to social and smoking status, as well as the knowledge and attitude towards cigarette smoking. The questionnaire takes around 10 minutes to be answered.

An interview questionnaire sheet was developed by the researchers in Arabic language to collect information which divided into 4 major sections were used in this study. Both open and close-ended questions were included in questionnaire. The first section contained the questions related to demographic data (Gender, age, marital status etc.) of the participants. Second section of the questionnaire which contained 3 questions in total was about the knowledge of students regarding effects of smoking on health. Third section was about the general attitude of participants regarding smoking and it contained 11 questions. In this section, mostly question was answerable by choosing the options among, "disagree, undecided or agree" option. This section contained questions like effect of smoking status of physicians on their patients and relationship of medical education on smoking prevalence among medical professionals. The fourth and last section contained 9 questions about the practicing of smoking among medical students and family members as well. Mostly questions in this question were of multiple choice questions type in which participant has to choose one or more than one option. Questions regarding smoking 
status of their family members were included in this section so that the correlation of family member's smoking status and smoking status of participants could be assessed.

\section{Data collection}

After obtaining the ethical approval from the Research Ethical Committee at Faculty of Applied Medical Sciences, King Abdalaziz University and once the participants who meet inclusion criteria are identified, the research assistants explained the aim of the questionnaire to all students. Then the questionnaires were distributed to the students after informed consent obtaining from all participants. The questionnaire was administered to participants in their classrooms in order to get maximum response rate. Sufficient time was allotted to fill in the questionnaire. If the participation rate was low in any class, a second visit was done to cover those students who were absent in the first session. Finally, questionnaire was collected from all the participants and the information contained in these questionnaires was saved.

\section{Data analysis}

Data was analyzed by using Statistical Package for the Social Sciences (SPSS) version 23. However, descriptive statistics were accomplished for the participant's knowledge, attitude and practice regarding smoking. Moreover, Chi- square test was used for categorical variables ( $\mathrm{p} \leq 0.05)$.

\section{Results}

\section{Demographic characteristics}

Out of 494 medical students participated in this study only 47 students (9.5\%) were smokers while remaining 447 (90.5\%) were not smokers. Average age of the participants was $20.56 \pm 1.93$ years, and $96.1 \%$ of the participants were from Jeddah area and $3.9 \%$ from outside Jeddah areas. There was an increase in smoking trend as the students were promoting from the second to fourth professional years that is in second professional year there was only 10 smokers $(6.3 \%)$ as compared to the fourth professional year which had 20 smokers $(11.2 \%)$ which means a double upsurge was observed in the presence of smokers when comparison was done between the second and fourth professional year. Third and fourth year had the same percentage of smokers' that is $10.8 \%$ and $11.2 \%$ respectively with a minor difference. However, second professional year had the least presence of smokers and they counted only 10 (6.3\%).While, the income of families per month imposes an influence on the smoking status of a person as the students who had reward and extra money sources were more prone to smoking as compare to the students had Reward only (18.3\% versus $8.3 \%$ ). Moreover, data depicts that tobacco usage was about 5 times (19.2\%) among males as compare to the smoking prevalence among females $(2.75 \%)$. Correspondingly, proportion of female nonsmokers $(97.2 \%)$ is much higher as compare to the non-smokers present among the male students (80.8\%). Finally, there was an increase in smoking trend as the students were resident alone to with family that was in resident alone there was only 3 smokers $(27.3 \%)$ as compared to with family where 37 smokers $(8.3 \%)$ which means a triple upsurge was observed in the presence of smokers when comparison was done between the resident alone and with family. However, resident with friends and resident alone had the same percentage of smokers' that was $27.3 \% \%$ and $20.0 \%$ respectively with a minor difference (Table 1 ).

Table 1: Demographic characteristics of study sample.

\begin{tabular}{|c|c|c|c|c|}
\hline \multicolumn{2}{|c|}{ Variable } & $\begin{array}{c}\text { Smokers } \\
\text { No. }(\%)\end{array}$ & $\begin{array}{c}\text { Not Smokers } \\
\text { No. (\%) }\end{array}$ & Total \\
\hline \multirow{2}{*}{ Age } & [19-21] & $19(5.3 \%)$ & $341(94.7 \%)$ & 360 \\
\hline & $>=22$ & $28(20.9 \%)$ & $106(79.1 \%)$ & 134 \\
\hline \multirow{2}{*}{ Gender } & Male & $39(19.2 \%)^{*}$ & $164(80.8 \%)$ & 203 \\
\hline & Female & $8(2.75 \%)$ & 283 (97.2\%) & 291 \\
\hline \multirow{2}{*}{ Marital Status } & - Single & 46 (9.5\%) & 436 (90.5\%) & 482 \\
\hline & -Married & $1(8.3 \%)$ & $11(91.7 \%)$ & 12 \\
\hline \multirow{3}{*}{ Current Professional Year } & 2nd Year & $10(6.3 \%)$ & $148(93.7 \%)$ & 158 \\
\hline & 3rd Year & $17(10.8 \%)$ & $140(89.2 \%)$ & 157 \\
\hline & 4th Year & $20(11.2 \%)$ & $159(88.8 \%)$ & 179 \\
\hline \multirow{4}{*}{ Scientific Department } & Medical Lab. Tech. & $10(9.1 \%)$ & $101(90.9 \%)$ & 111 \\
\hline & Physical Therapy & $26(12.9 \%)$ & $176(87.1 \%)$ & 202 \\
\hline & Diag. Radiology & $7(6.7 \%)$ & $98(93.3 \%)$ & 105 \\
\hline & Clinical Nutrition & $2(2.6 \%)$ & $74(97.4 \%)$ & 76 \\
\hline \multirow{3}{*}{ Residency } & With Family & $37(8.3 \%)$ & $411(91.7 \%)$ & 448 \\
\hline & With Friends & $7(20.0 \%)$ & $28(80.0 \%)$ & 35 \\
\hline & Alone & $3(27.3 \%)$ & $8(72.7 \%)$ & 11 \\
\hline
\end{tabular}


International Journal of Pulmonary \& Respiratory Sciences

\begin{tabular}{|c|c|c|c|c|}
\hline \multirow{2}{*}{ Place of Residence } & Jeddah & $42(8.8 \%)$ & $433(91.2 \%)$ & 475 \\
\cline { 2 - 5 } & Outside Jeddah & $5(26.3 \%)$ & $14(73.7 \%)$ & 19 \\
\hline \multirow{2}{*}{ Monthly Income } & - Reward only & $36(8.3 \%)$ & $398(91.7 \%)$ & 434 \\
\cline { 2 - 5 } & - Reward and extra sources & $11(18.3 \%)$ & $49(81.7 \%)$ & 60 \\
\hline
\end{tabular}

Knowledge of students regarding smoking effects on were the most common complication about which students health

knew their association with the smoking in a well manner. In

Generally, all the FAMS students (98.9\%) participated in this study were well aware about the harmful effects of smoking irrespective of their medical professional year. However only 5 students (1.1\%) out of 494 FAMS students took the effects of the smoking in a positive way that smoking is beneficial during the examination period, as nicotine stimulates the nervous system and improves the cognitive ability. In addition, FAMS Students had thorough knowledge of the major diseases which are directly or indirectly associated with smoking. However, Table 2 depicts the familiarization of 494 FAMS students regarding a number of diseases and malignancies which are linked with usage of tobacco. From the table it is clear that, lung malignancies and other pulmonary diseases (bronchitis, emphysema, COPD etc.) this regard, 472 students (95.5\%) were acquainted with the bronchitis, emphysema, COPD etc. and 470 students (95.1\%) knew that lung malignancies were directly related with smoking. However, a very few number of students $(0.4 \%)$ had knowledge regarding link of lung malignancies with the smoking. On the contrary, malignancies, which are apart from lungs and including other organs as breast, urinary bladder etc. were the least complications about which students, had knowledge about it. Approximately $74.7 \%$ of the students were well aware about relation of such malignancies with the smokers. Likewise, longterm complications like hypertension and hypercholesterolemia, which are the results of regular smoking, were well acquainted among the medical students $(77.1 \%)$.

Table 2: knowledge level of FAMS students regarding various diseases associated with smoking.

\begin{tabular}{|c|c|c|c|}
\hline Smoking Related Complications & Unfamiliar No. (\%) & Some knowledge No. (\%) & Familiar No. (\%) \\
\hline Lung Malignancies & $2(0.4)$ & $16(3.2)$ & $472(95.5)$ \\
\hline $\begin{array}{c}\text { Other Pulmonary Diseases (Bronchitis, } \\
\text { Emphysema, COPD etc.) }\end{array}$ & $4(0.9)$ & $20(4)$ & $470(95.1)$ \\
\hline $\begin{array}{c}\text { Malignancies apart from Lungs (Breast, urinary } \\
\text { bladder etc.) }\end{array}$ & $63(12.7)$ & $62(12.5)$ & $369(74.7)$ \\
\hline $\begin{array}{c}\text { Chronic adverse Health Effects (Hypertension, } \\
\text { Hypercholesterolemia) }\end{array}$ & $52(10.5)$ & $61(12.3)$ & $381(77.1)$ \\
\hline
\end{tabular}

\section{General attitude of FAMS students regarding smoking}

Table 3 represents the general attitude of medical students regarding smoking usage and influence of friends and family members who smoke, on themselves. About $86.6 \%$ students thought that there is a solid inspiration of smoking on the nonsmoker members of a family if a family member smokes. Chances of becoming a smoker for a non-smoker are increased up to more than $94 \%$ if a person has smoking friends as compared to smoking family members. Similarly, 416 students (84.2\%) out of 494 had same thought in this regard that if someone smokes in

a community it can disturb his or her relation with the others. In addition, only $25.1 \%$ students considered that they could be open to their guardians regarding their tobacco usage as compare to $60.9 \%$ students who preferred to be quiet about their tobacco usage. Moreover, smoking status can affect smoker's relation with someone fellows or friends and this is the reason that 411 students (83.2\%) also had the same opinion. Likewise, in the opinion of 470 (95.1\%) medical students if they smoke, it will not inspire the others to smoke, as smoking is based on person's own discretion usually.

Table 3: General attitude of FAMS students regarding smoking.

\begin{tabular}{|c|c|c|c|}
\hline \multirow{2}{*}{ Questions Type } & \multicolumn{3}{|c|}{ Response No. (\%) } \\
\hline & Disagree & Undecided & Agree \\
\hline $\begin{array}{l}\text { You think people are influenced by their family members who } \\
\text { are smokers? }\end{array}$ & $41(8.3)$ & $25(5.1)$ & $428(86.6)$ \\
\hline $\begin{array}{l}\text { Do you think people are influenced by their friends who are } \\
\text { smokers? }\end{array}$ & $9(1.8)$ & $16(3.2)$ & $469(94.9)$ \\
\hline $\begin{array}{l}\text { Do you think your smoking status affects your relations with } \\
\text { the others? }\end{array}$ & $35(7.1)$ & $43(8.7)$ & $416(84.2)$ \\
\hline $\begin{array}{l}\text { Would you like to be open to your parents about your smoking } \\
\text { status? }\end{array}$ & $301(60.9)$ & $69(13.9)$ & $124(25.1)$ \\
\hline Do you feel more acceptable if you smoke? & $411(83.2)$ & $65(13.2)$ & $18(3.6)$ \\
\hline Will you encourage others to smoke? & $470(95.1)$ & $8(1.6)$ & $16(3.2)$ \\
\hline
\end{tabular}


International Journal of Pulmonary \& Respiratory Sciences

Table 4: General attitude of FAMS students regarding influence of education and smoking.

\begin{tabular}{|c|c|c|c|}
\hline \multirow{2}{*}{ Questions Type } & Response No. (\%) & & \\
\hline & Disagree & Undecided & Agree \\
\hline The Ministry of Health in Saudi Arabia is working properly to reduce smoking? & 184(37.3) & $167(33.8)$ & 143(28.9) \\
\hline Statuary warnings on the cigarettes packs are enough to limit smoking? & $379(76.8)$ & $62(12.5)$ & $53(10.7)$ \\
\hline Do you think education helps to reduce smoking trends? & $120(24.3)$ & $123(24.9)$ & $251(50.8)$ \\
\hline $\begin{array}{l}\text { If medical students and doctors smoke, does it convey negative message to } \\
\text { patients/public? }\end{array}$ & $35(7.1)$ & $43(8.7)$ & $416(84.2)$ \\
\hline
\end{tabular}

Table 4 represents the attitude of medical students about association of education and usage of tobacco, and about the initiatives, which has taken by the government to halt the smoking. From the table it can be illustrated that more than $37 \%$ of the students were very unsatisfied by the steps that Ministry of Health in Saudi Arabia has taken to reduce the usage of tobacco in the country. Moreover, in the opinion of 379(76.8\%) students' statuary warnings that is imposed by the cigarette manufacturing companies on the cigarette packs are not enough that it can help or motivate a smoker to quit smoking. Educational level of a person is the major obstacle which can prevent a person to indulge yourself in smoking, and 251 students (50.8\%) had the same opinion in this regard, however less than quarter of the total students $(24.3 \%)$ thought that education has nothing to do with a person's choice regarding usage of tobacco. More than $84 \%$ of the medical students contemplated that as the medical professionals and medical students are the prime model of health for the society so if they smoke then it may discourage a patient to give up his or her smoking habit.

\section{General Performance regarding smoking}

Regarding usage of electronic cigarette is not as common in Saudi Arabia as it is a contemporary way of consuming tobacco and this is the reason that FAMS students had not much cognizance about such practice of tobacco smoke inhalation. Out of 494 FAMS students, only 26 participants (5.3\%) had ever heard about electronic cigarette whereas remaining never heard about its usage among the smokers. Concerning the intake of the antismoking drugs offered by the Ministry of Health in Saudi Arabia, out of 47 FAMS smoker students, only 3 participants (6.4\%) had ever used these anti-smoking drugs whereas remaining never used these drugs among the smokers. However, Table 5 categorizes the students as a smoker and non-smoker according to the presence of smoker or non-smoker family member within the family. If a family member smoke in a family, it definitely effects the other members of the family who are non-smokers ( $p$-value $=0.013)$. Therefore, it is concluded that students who had smoking family member in their family were more likely to become tobacco user as compared to students who did not have any family member who smoke. Out of 47 smoking medical students, 31 medical students (8.1\%) had smoking family member whereas families of 16 FAMS students (14.7\%) did not have any smoking family member (Table 5).

Table 5: Influence of smoking family member on medical student's smoking status.

\begin{tabular}{|c|c|c|c|}
\hline Chi-square test & $\begin{array}{c}\text { Smokers } \\
\text { No. (\%) }\end{array}$ & $\begin{array}{c}\text { Non-smokers } \\
\text { No. (\%) }\end{array}$ & p-value \\
\hline $\begin{array}{c}\text { Student's family having smoker } \\
\text { No. (\%) } 385(77.9 \%)\end{array}$ & $31(8.1)$ & $354(91.9)$ & 0.013 \\
\hline $\begin{array}{c}\text { Student's family having no smoker No. } \\
(\%) 109(22.1 \%)\end{array}$ & $16(14.7)$ & $93(85.3)$ & \\
\hline
\end{tabular}

Concerning the anti-smoking campaigns, there was very less proportion of FAMS students who had participated in some sort of anti-smoking campaign to play their role as medical professionals to tackle the problem of smoking in their community. Out of 494 medical students, only 139(28.1\%) FAMS students had attended anti-smoking campaign in their career (Table 6).

Table 6: Participation of medical students in anti-smoking campaign.

\begin{tabular}{|c|c|}
\hline $\begin{array}{c}\text { Medical Professional Year } \\
\text { (Total no. of students) }\end{array}$ & $\begin{array}{c}\text { Participation in Anti-Smoking Campaign } \\
\text { No. (\%) }\end{array}$ \\
\hline $2^{\text {nd }}$ Year & $48(9.7)$ \\
\hline $3^{\text {rd }}$ year & $44(8.9)$ \\
\hline $4^{\text {th }}$ Year & $47(9.5)$ \\
\hline
\end{tabular}




\section{Discussion}

Smoking has been classified by the WHO as an epidemic because of its fast spread among peoples and its dangerous effect on human worldwide [13]. However, our study showed that the total percentage of FAMS students who are currently smoking was $9.5 \%$.The findings of this study confirm lower smoking prevalence among high schools and Universities students in other region and cities in Saudi Arabia. A high prevalence of adolescent and young adult smoking was also reported in recent Saudi studies conducted in Jeddah [14] and Riyadh [15]. The reported prevalence rates in those studies were 37\%, 29.0\% and $31.0 \%$, respectively, with a significant higher prevalence of smoking among male compared to female students in a study conducted in Riyadh study [15]. In addition, a cross-sectional study was conducted to assess the smoking prevalence among dental students at King Saud University revealed that the overall $17 \%$ of the sampled students reported that they are current smokers [16]. Although this prevalence seems to be high considering their work in a health-related profession, similar prevalence rates have been reported among medical students. For example, Al-Kaabba and colleagues reported that $18 \%$ of medical students in Riyadh, Saudi Arabia smoked [17]. Similarly, Al-Haqwi and colleagues found that $19 \%$ of students smoked in two new medical colleges in Riyadh [12]. In a review of smoking rates among dental students in 19 countries, Smith and colleagues reported rates between $3 \%$ in Canada to $47 \%$ in Greece [18]. Moreover, the findings of the Agilley and colleagues study indicated that, the percentage of smokers among students of health colleges is only $8 \%$ [19]. The low percentage of health care students who smoke may be due to the greater awareness of them with respect to tobacco, to being health care professionals and being able to see its pernicious effects directly in their daily clinical practice. These results were agreed with previous study which shown that the prevalence of smokers among dentists is considered a small percentage compared with the public [20].

Regarding gender, our results revealed that tobacco usage was about 5 times (19.2\%) among males as compare to the smoking prevalence among females $(2.75 \%)$. The findings of this study confirm similar smoking prevalence among high schools and Universities students in other region and cities in Saudi Arabia [21], these findings consistent with other studies [12,17,22,23]. In addition, Al-Swuailem and colleagues found a significant difference in smoking rates between male (27.8\%) and female (2.4\%) dental students [16]. However, these results agreed with Agilley and colleagues reported that smoking behaviors are more prevalent among males than females [19]. Lower smoking rates among female students could reflect the fact that smoking by females is culturally unacceptable, especially in conservative societies like Saudi Arabia [18,24].

Concerning comparison between senior year students and junior year students Tobacco smoking, There was an increase in smoking trend as the students were promoting from the second to fourth professional years. These findings agreed with Alrehaili and colleagues found significantly higher rate of smoking among the former student group [21]. In contrast, previous studies conducted at Saudi Arabia have been reported the same findings regarding age group in addition to other studies found higher smoking rates among senior dental students than junior students [25,26]. Moreover, Newbury-Birch and colleagues assessed changes in smoking rates among 47 dental students in the University of Newcastle, UK, in the second year, fifth year, and 1 year after graduation. In that study, the prevalence of cigarette smoking dropped as students' progress in school from $11 \%$ in the second year to $4 \%$ and $6 \%$ in the fifth year and after graduation as dentists, respectively [27]. This higher rate of smoking among students of the fourth professional years is probably due to increased stress faced by the students with their progression, over the years.

The results of the present study showed that chances of becoming a smoker for a non-smoker are increased up to more than $94 \%$ if a person has smoking friends, so that the main reason for smoking is the pressure and simulation of their friends practiced smoking. These results are congruent with findings of previous studies reported that, friends were considered the major reason for starting smoking [25,26,28,29,30]. The effect of having close friends that smoke may increase the rate of smoking among medical students in Saudi Arabia as much as 5-fold [28].

We found an association between the presence of a smoking family member (father, mother, brother, or sister) and smoking habits. This finding agreed with the findings of Dar-Odeh and his group who reported a significant association between student and parental smoking habits [29]. Similarly, for students in the College of Applied Medical Sciences at King Saud University reported that the existence of smoking parents or siblings was significantly associated with higher rates of smoking among students [30]. Similarly in several studies, parental smoking was an important risk factor in adolescents' and young adults' smoking $[3,4,14,15,21]$ and international studies [31,32]. As most of youths look up to their parents and other close relatives in their society and attempt to mimic their demeanor, parents smoking showed to be the most important factor related to adolescents and young adults smoking in this and other studies [33].

Concerning knowledge level of FAMS students regarding various diseases associated with smoking, about $99 \%$ of students participated in this study were well aware about the harmful effects of smoking irrespective of their medical professional year. These findings agreed with findings of many previous studies [34-36] as our study results showed that Applied Medical Sciences students are more knowledgeable and aware about smoking negative effects and showed greater willingness to stop smoking than non- medical students do. This may be explained as curriculum courses of medical specializationsin general- addresses to smoking hazardous effects and how 
to stop smoking. Despite their awareness, about $9.5 \%$ of the medical students in this study keep on smoking, it is obvious from the results of this study that there is defect in advisory and educational roles of health and community organizations in spreading health awareness in society, and this will affect the behaviors of citizens toward smoking especially young people [37].

Concerning the anti-smoking campaigns, there were only $28.1 \%$ of FAMS students participated in some sort of antismoking campaign to play their role as medical professionals to tackle the problem of smoking in their community. However, more than $37 \%$ of the students were very unsatisfied by the steps that Ministry of Health in Saudi Arabia has taken to reduce the usage of tobacco in the country. Moreover, less than quarter of the total students $(24.3 \%)$ thought that education has nothing to do with a person's choice regarding usage of tobacco. The active participation of healthcare providers in tobacco cessation programs is important because most smoking patients either want or have attempted to stop smoking, but have failed due to uncertainty on "how to quit" [24]. Thus, a gap exists between the knowledge of tobacco health risks and the level of training in tobacco counseling among students [38,39]. The available literature encourages reforming curricula to accommodate tobacco cessation programs $[23,40]$.

The present study has points of strengths and limitations. Strengths of this study include being a university-based with a high response rate from the participated students, and according to our best knowledge, this study is the first to study smoking habit and attitudes among Faculty Applied Medical Sciences male students of King Abdul-Aziz University. However, limitations of this study include using a self-administered questionnaire without validation of the collected data through biochemical tests due to financial constraints, which might underestimate the actual prevalence of smoking in the studied students. One limitation of this study is related to the issue of validity for selfreported information, a common issue for surveys.

\section{Conclusion}

The current study revealed a considerable high prevalence of smoking among students in Faculty of Applied Medical Sciences, King Abdul-Aziz University, Jeddah City, Saudi Arabia. One of the major and important findings of this current study was the positive attitudes of all studied students and smokers in particular towards smoking. This finding of this study has to motivate and encourage the Ministry of Health to increase the number of smoking clinics and activate them and make them more popular and attract the smoker students to utilize helping them to quit smoking. In addition, it would be very helpful to organize smoking campaigns in the various faculties at the university to increase the awareness about the dangerous of smoking.

\section{Recommendations}

From the results of current study, it recommend to:

a. Critically integrate cessation-counseling training into medical and non-medical sciences education.

b. Develop educational program for people early in adolescence stage, and activate the role of medical related organization in spreading health awareness in the community.

c. Medical students must be acquainted with the latest methods of smoking like electronic cigarettes, so that they can deal with their patients with full competency.

d. It should be compulsory for all the medical students to be involved in some anti-tobacco policies and programs and similar workshops regarding smoking cessation techniques and other related matters so that before practicing as professional doctors they become fully trained in this field.

e. Introduce special courses for smoking behaviors and cessation in the curriculum for medical students to increase their awareness and encourage them to stop smoking and this boost their credibility as health care providers especially in cases of health education and consultation.

f. Activate the celebration of World No Tobacco Day on 31st May each year.

g. In addition, it would be very helpful to organize smoking campaigns in the various faculties at the university to increase the awareness about the dangerous of smoking.

\section{Acknowledgment}

The authors acknowledge with thanks all students who shared in distribution of survey and collection students response to the survey.

\section{References}

1. World Health Organization (WHO) Tobacco. Geneva, Switzerland.

2. World Health Organization (2015) Prevalence of tobacco smoking, age standardized prevalence of current tobacco smoking among persons aged 15 years and older. WHO, Geneva, Switzerland.

3. Bassiony MM (2009) Smoking in Saudi Arabia. Saudi Med J 30(7): 876881.

4. Al Nohair S (2011) Prevalence of Smoking and its Related Behaviors and Beliefs among Secondary School Students in Riyadh, Saudi Arabia. Int J Health Sci (Qassim) 5(1): 51-57.

5. Mandil A, BinSaeed A, Dabbagh R, Shaikh SA, AlSaadi M, et al. (2011) Smoking among Saudi university students: consumption patterns and risk factors. Eastern Mediterranean health journal 17(4): 309-316.

6. Alrsheedi M, Abdul Haleem (2012) knowledge, attitude and behavior of medical and dental students towards smoking habit in Saudi Arabian universities 'a comparative study'. Int Dent Students Res 1(1): 61-77.

7. Alqahtani JM (2017) Knowledge, attitude and practice of tobacco smoking among health colleges' students at Najran University, Saudi 
Arabia: A cross-sectional descriptive study. Int Dent J of student's research 5(1): 33-41.

8. Zhu T, Feng B, Wong S, Choi W, Zhu SH (2004) A comparison of smoking behaviors among medical and other college students in China. Health Promot Int 19(2): 189-186.

9. Hamadeh RR (1994) Smoking habits of medical students in Bahrain. Journal of smoking related disorders 5: 189-194.

10. Alqarni A, Nuqali A, Al Sharif A (2016) Trends of smoking habits among medical students at umm al-qura University, faculty of medicine.

11. Franco JA, Trullén A, García A, Marrón R, Clemente ML, et al. (2004) Tobacco Use of Tobacco Among Young People in Informal Education Settings: a Survey of Behaviors and Opinions. p. 10-16.

12. Al Haqwi A, Tamim H (2010) Knowledge, attitude and practice of tobacco smoking by medical students in Riyadh, Saudi Arabia. Ann Thorac Med 5(3): 145-148.

13. World Health Organization (2003) The World Health Report: Shaping the Future. WHO, Geneva, Switzerland.

14. Fida RH, Abdelmoneim I (2013) Prevalence of smoking among secondary school male students in Jeddah, Saudi Arabia: a survey study. BMC Public Health 13: 1010.

15. Al Ghobain MO, Al Moamary MS, Al Shehri SN, Al Hajjaj MS (2011) Prevalence and characteristics of cigarette smoking among 16-18 years boys and girls in Saudi Arabia. Ann Thorac Med 6(3): 137-140.

16. Al Swuailem A, AlShehri M, Al Sadhan S (2014) Smoking among dental students at King Saud University: Consumption patterns and risk factors. The Saudi Dental Journal 26(3): 88-95.

17. Al Kaabba AF, Saeed AA, Abdalla AM, Hassan HA, Mustafa AA, et al. (2011) Prevalence and associated factors of cigarette smoking among medical students at King Fahad Medical City in Riyadh of Saudi Arabia. J Family Community Med 18 (1): 8-12.

18. Smith DR, Leggat PA (2007) An international review of tobacco smoking among dental students in 19 countries. Int Dent J 57(6): 452458.

19. Agilley A, Aboalshamat K, Elkwatehy W, Akbar L (2017) Smoking prevalence and attitude among health sector students in Um Al-Qura University, Saudi Arabia. Int J Adv Res 5(3): 124-128.

20. Peidró CE, Romero OS, Sala CE (2008) Prevalence of smoking among dentists in Catalonia--Spain(2006). Literature review of smoking cessation practices in the dental office. Med Oral Patol Oral Cir Bucal 13(10):E 671-E677.

21. Alrehaili A, Felemban A, Felemban W, Alharbi A, Ekhmimi Y (2017) Knowledge, Attitude and Practice of Cigarette Smoking among Male Students of Taibah University, Al Madinah, Saudi Arabia. International Journal of Science and Research 6(1): 385-388.

22. Alomari Q, Barrieshi Nusair K (2006) Smoking prevalence and its effect on dental health attitudes and behavior among dental students. Med Princ Pract 15 (3): 195-199.

23. Khami MR, Murtomaa H, Razeghi S, Virtanen JI (2010) Smoking and its determinants among Iranian dental students. Med Princ Pract 19 (5): 390-394.

24. Memon A, Moody PM, Sugathan TN, el Gerges N, al Bustan M, et al. (2000) Epidemiology of smoking among Kuwaiti adults: prevalence, characteristics, and attitudes. Bull World Health Organ 78 (11): 13061315.
25. Dumitrescu AL (2007) Attitudes of Romanian dental students towards tobacco and alcohol. J Contemp Dent Pract 8 (3): 64-71.

26. Underwood B, Fox K (2000) A survey of alcohol and drug use among UK based dental undergraduates. Br Dent J 189 (6): 314-317.

27. Newbury Birch D, Lowry RJ (2002) The changing patterns of drinking, illicit drug use, stress, anxiety and depression in dental students in a UK dental school: a longitudinal study. Br Dent J 192(11): 646-649.

28. Merdad LA, Al Zahrani MS, Farsi JM (2007) Smoking habits among Saudi female university students: prevalence, influencing factors and risk awareness. Ann Saudi Med 27(5): 366-369.

29. Dar Odeh NS, Bakri FG (2010) Narghile (water pipe) smoking among university students in Jordan: prevalence, pattern and beliefs. Harm Reduct J 7: 10.

30. Hasim TJ (2000) Smoking habits of students in College of Applied Medical Science, Saudi Arabia. Saudi Med J 21(1): 76-80.

31. Kristjansson AL, Sigfusdottir ID, Allegrante JP, Helgason AR (2008) Social correlates of cigarette smoking among Icelandic adolescents: a population-based cross sectional study. BMC Public Health 8: 86.

32. Damianaki A, kaklamani S, Tsirakis S, Clarke R, Tzanakis N, et al. (2008) Risk factors for smoking among school adolescents in Greece. Child care Health Dev 34(3): 310-315.

33. Al Zalabani A, Kasim K (2015) Prevalence and predictors of adolescents' cigarette smoking in Madinah, Saudi Arabia: a school-based crosssectional study. BMC Public Health 15: 17.

34. Hashim T (2000) Smoking habits of students in College of Applied Medical Science, Saudi Arabia. Saudi Med J 21(1): 76-80.

35. Adeyeye $O$ (2011) Cigarette smoking habits among senior secondary school students in lagos, south west Nigeria, International Journal of Biological \& Medical Research. Int J Biol Med Res 2(4): 1047-1050.

36. Ferrante M, Saulle R, Ledda C, Pappalardo R, Fallico R, et al. (2013) Prevalence of smoking habits, attitudes, knowledge and beliefs among Health Professional School students: a cross-sectional study. Ann Ist Super Sanità 49(2): 143-149.

37. Gfroerer JC, Greenblatt JC, Wright DA (1997) Substance use in the US college-age population: differences according to educational status and living arrangement. American journal of public health 87(1): 6265.

38. Centers for Disease Control and Prevention (CDC) (2005) Tobacco use and cessation counseling-global health professionals survey pilot study, 10 countries, 2005. MMWR Morb Mortal Wkly Rep 54(20): 505509.

39. Warren CW, Sinha DN, Lee J, Lea V, Jones N, et al (2011) Tobacco use, exposure to secondhand smoke, and cessation counseling training of dental students around the world. J Dent Educ 75(3): 385-405.

40. Taha AZ, Sabra AA, Al Mustafa ZZ, Al Awami HR, Al Khalaf MA, et al. (2010) Water pipe (shisha) smoking among male students of medical colleges in the eastern region of Saudi Arabia. Ann Saudi Med 30(3): 222-226. 
This work is licensed under Creative
Commons Attribution 4.0 Licens
DOI: 10.19080/IJOPRS.2018.02.555595
Your next submission with Juniper Publishers

$$
\text { will reach you the below assets }
$$

- Quality Editorial service

- Swift Peer Review

- Reprints availability

- E-prints Service

- Manuscript Podcast for convenient understanding

- Global attainment for your research

- Manuscript accessibility in different formats

( Pdf, E-pub, Full Text, Audio)

- Unceasing customer service

Track the below URL for one-step submission https://juniperpublishers.com/online-submission.php 